Página inicial: 441 - Página Final: 461

Tipo de artículo: Investigación

\title{
Normalización sin transición: la dimensión territorial del proceso de paz en la Zona Veredal de Transición y Normalización (ZVTN) de La Macarena'
}

\author{
Normalization without Transition. Territorial Dimension of the Peace Process in the \\ Transitional Village Zones of Normalization (ZVTN) of Sierra de la Macarena
}

\author{
Recibido: abril de $2017 \quad$ Revisado: mayo de $2017 \quad$ Aceptado: junio de 2017
}

Por: Keren X. Marín ${ }^{1}$ \& Nicolás Espinosa Menéndez ${ }^{2}$

1 Politóloga. Joven investigadora Universidad de Antioquia. Estudiante de Maestría en Antropología, Univerisidad de los Andes. Bogotá (Colombia). Contacto: kx.marin@uniandes.edu.co

2 Sociólogo. $\mathrm{PhD}(\mathrm{c})$ Antropología. Docente Universidad de San Buenaventura Medellín, Integrante del grupo Cultura, Derecho y Ciudad de la Facultad de Derecho. Medellín (Colombia). Contacto: nicolas.espinosa@usbmed.e du.co

ORCID:

https://orcid.org/0000$\underline{0001-6683-5391}$

\section{Resumen}

En la Sierra de la Macarena se ubican tres de las 26 Zonas Veredales Transitorias de Normalización (ZVTN), dispuestas en los acuerdos de la Habana como lugares para concretar el cese bilateral y definitivo de hostilidades. Las Zonas han supuesto el espacio para el desarme y reincorporación a la vida civil de los combatientes de las FARC- EP. Una de tales Zonas se encuentra en inmediaciones de los llanos del Yarí en el poblado de Playa Rica. La historia de este territorio da cuenta de los conflictos propios de la colonización del piedemonte amazónico y de los impactos de la guerra civil. La adecuación de la Zona Veredal ha significado para las comunidades de la región la posibilidad de hallar cierta presencia del estado central que, sin su tradicional carácter contrainsurgente, ha sido objeto de crecientes movilizaciones sociales. Sin embargo, la incapacidad institucional para reconocer la historia organizativa y social de El Yarí, el pesado aparato burocrático que ralentiza la implementación de los acuerdos, así como los vacíos de poder que la disidencia de la guerrilla pretende copar, han implicado que en la Zona Veredal confluya un escenario social de normalización sin transición.

Palabras clave. Zona Veredal Transitoria de Normalización; ZVTN; Proceso de Paz en Colombia; FARC-EP; Construcción de Paz; Sierra de La Macarena.

\begin{abstract}
In the Sierra de la Macarena 3 out of the 26 Transitional Village Zones of Normalization (ZVTN) are located, as it was arranged in the agreements of Havana as places to put an end to bilateral and definitive cessation of hostilities. The Zones have represented a space for disarmament and reintegration into the civilian life of the combatants of FARC - EP. One of such zones is located in the immediate vicinity of Yari plains, in the town of Playa Rica. The history of this area provides the conflicts of colonization of the Amazon Foothill and the impacts of the civil war. The adequacy of the Village Zone, for the communities of the region, has meant the possibility of finding some presence of the central State that, without its traditional counterinsurgency character, has been the subject of growing social mobilizations. However, the institutional inability to recognize the organizational and social history of the El Yari, the heavy bureaucratic apparatus that slows down the implementation of the agreements, as well as the power vacuum that the dissidence of the guerrilla aims to copy, have implied that in the Village Zone merge a social scenario of normalization without transition.
\end{abstract}

Key words: Transitional Village Zones of Normalization (ZVTN); Colombian Peace Process; FARC-EP; Construction of Peace; Sierra de la Macarena. 


\section{Introducción}

El pasado 27 de junio de 2017 en la casa del promotor local de DD.HH. de La Macarena, Aparicio Garcíai ${ }^{\text {ii }}$ vimos la trasmisión de la ceremonia que dio fin al proceso de dejación de armas de las FARC EP. Cuando los delegados de la ONU confirmaron que el 100\% de las armas que portaba esta guerrilla estaban debidamente almacenadas, Aparicio recogió las dudas y ansiedades que rodean al proceso de paz en La Macarena diciéndonos que "la pregunta que nos hacemos en la región es qué va a pasar desde hoy". Tal vez parte de la respuesta pueda encontrarse en la reciente experiencia de las Zonas Veredales Transitorias de Normalización (ZVTN, cfr. OACP 2016), lugares donde las FARC EP se concentraron para dar lugar a la dejación de armas, sentar las bases para su conversión en partido político e iniciar el camino para su reincorporación a la vida civil.

Estas Zonas fueron definidas conforme un capítulo especial de los acuerdos de la Habana, firmados por el estado colombiano y las FARC EP, para concretar el fin de la guerra (cfr. OACP 2016b). Puesto que el acuerdo de la Habana fue planteado desde una perspectiva transicional, la implementación de las Zonas se enmarca en distintas apuestas por la construcción de paz; una estas, tal vez la definitiva, consiste en la dejación de las armas como paso previo a la participación política legal de las FARC EP. Para tal efecto en los acuerdos fue previsto en un engorroso protocolo que supuestamente tomaría un espacio/tiempo delimitado, cuya expresión concreta son las 26 Zonas Veredales (OACP 2016c) y cuya realidad social desbordó las expectativas iniciales (Cfr. Carrillo 2017).

Estas Zonas han supuesto un nuevo territorio dentro del inventario espacial del conflicto armado en Colombia (Cfr. Hoyos 2017) en tanto representan el último lugar de la guerra y el primero para la construcción de paz. Por ello creemos que la pregunta de Aparicio encuentra algunas pistas en el análisis de la experiencia regional de las Zonas Veredales, pues allí nos ha sido posible observar los complejos retos que la paz implica. En nuestro artículo daremos cuenta de la forma en que el proceso de transición territorial permite observar las tensiones que la normalización implica para las comunidades vecinas de la Zona Veredal Urías Rondón, ubicada en el Caserío Playa Rica. Cabe mencionar que una de esas tensiones tiene que ver con el sistemático asesinato de líderes sociales en la región; en la casa de Aparicio un mural con la figura de Erley Monroy nos recuerda que este carismático líder de la Asociación Campesina Ambiental Lozada-Guayabero (ASCAL-G) fue asesinado el pasado 18 de noviembre de 2016 a pocos kilómetros del Batallón Cazadores de San Vicente del Caguán (El Heraldo, 2016b).

Nuestra historia empieza, pues, pocos días después del asesinato de Monroy, en diciembre de 2016, cuando en La Macarena supimos que el poblado de Playa Rica sería el lugar de concentración de la guerrilla. Aunque se daba por descontado que el punto podría ser la Vereda El Diamante en los llanos del Yarí, lugar donde se llevó a cabo la X Conferencia Guerrillera, varios allegados a las FARC EP nos dijeron que no tenía sentido, pues la guerrilla pensaba en salirse de la selva "hacia afuera" para estar cerca de "las masas", ya que allá es donde el proyecto político apunta. El Diamante, en suma, queda muy lejos de todo y de todos. Playa Rica, en cambio, un poblado fundado hace dos décadas al amparo del proyecto insurgente, es un punto central.

Como preámbulo para la instalación de la Zona, en enero de 2017 varias comunidades de La Macarena fueron invitadas a una reunión convocada por el Mecanismo de Monitoreo y Verificación en Playa Rica. A esta asistieron representantes de Juntas de Acción Comunal, Asociaciones 
Campesinas y quienes por cosas de la vida estábamos justo ese día, en ese preciso lugar. Tras la presentación de rigor del representante del Mecanismo y una breve explicación sobre los integrantes y papel del mismo, la perspectiva del encuentro (exponer el carácter y alcance del monitoreo, resolver dudas en torno al proceso de dejación de armas y explicar la naturaleza de la Zona Veredal) fueron superadas por el tipo de discusión propuesta por las comunidades.

Todos comentamos lo curioso que resultaba la presencia tranquila de policías en un poblado de tradición insurgente donde nunca antes habían hecho presencia, mientras que varias personas no salían de su asombro al ver que Militares y Guerrilleros, desarmados, realizaban las labores previas de instalación de la Zona Veredal. Hasta hace menos de un año los combates y la presión militar sobre la población eran cosa común. Playa Rica es uno de esos lugares donde la guerra se ha sentido con mayor intensidad, donde el proyecto político de las FARC EP y las políticas contrainsurgentes dejaron sus marcas. La llegada de la paz fue, por supuesto, bienvenida.

No obstante, aunque con la paz lleguen representantes institucionales, para los líderes sociales resulta desafortunado el desconocimiento estatal de la perspectiva territorial que las comunidades de El Yarí reivindican. Para Gustavo Pérez, un líder local de la región, esta perspectiva implica el reconocimiento de la tradición política y organizativa en la región que supone la participación de las comunidades en las discusiones en torno a la definición social y política de El Yarí. Eso implica, en consecuencia, que como puesta por la paz las comunidades de la región exigen su inclusión como actores centrales en la planeación de políticas públicas asociadas a las Zonas Veredales.

La discusión desbordó el alcance de la invitación del Mecanismo pues, según ellos, no están para estos menesteres. Como tampoco para tratar otros tantos temas que hicieron su aparición: las quejas por el avance de la erradicación forzada de cultivos de coca que desde 2015 (tras el repliegue de la guerrilla) adelanta el ejército, la denuncia por la inédita presencia de delincuencia común; el problema del litigio limítrofe entre los departamentos del Meta y Caquetá que la instalación del Mecanismo parece profundizar (para la gente del Caquetá resulta un insulto que el Mecanismo dependa de una regional del Meta) y la impotencia que la gente tiene ante las amenazas que la disidencia de las FARC EP implican para las comunidades.

El delegado de la ONU se comprometió a llevar las inquietudes a las instancias pertinentes pues, insistió, el Mecanismo no tiene por objeto tratar tales problemas. Sin embargo, conforme el paso de los días en cada espacio convocado por el Mecanismo las demandas se hicieron más amplias: qué por qué no avanza la interconexión eléctrica, qué dónde está el centro de salud, qué a ver el acueducto. La posibilidad de respuesta del Mecanismo, limitada a servir de puente entre comunidades e instituciones, no llenó las expectativas de comunidades que por primera vez en su historia no solo han sentido cerca una presencia civil del estado, sino que dicha presencia tiene una expresión material.

Finalmente, desde febrero de 2016 el Mecanismo canceló toda reunión con las comunidades, sobre todo por la latente amenaza de una toma de sus instalaciones propuesta por algunas comunidades como estrategia de presión. Días antes los exasperados delegados de la ONU respondieron a la comunidad que ellos no eran responsables de proveer justicia o garantizar seguridad, por lo que debían comunicarse con las instituciones correspondientes. Don Josefo, presidente de la vereda el Yamú, preguntó en tono burlón a qué institución acudir si no había ninguna. La ONU decidió delegar el trabajo de pedagogía de la paz a los representantes de las FARC EP. 
A partir del análisis de estas tensiones entre comunidades y la reciente institucionalidad presente en Playa Rica, nuestro propósito es exponer la forma a través de la cual la instalación de la Zona Veredal como experiencia territorial supone una normalización sin transición, es decir, un estado de cosas donde se cruzan no sólo la materialización de los acuerdos, sino que han tomado lugar de manera simultánea conflictos sociales pasados y presentes. Esta situación ha implicado que las apuestas transicionales de los acuerdos encaminadas a la normalización se hayan visto desafiadas por situaciones no previstas en los acuerdos.

Para dar cuenta de esta ello, nuestro artículo se divide en cuatro secciones: la primera recoge los antecedentes políticos y sociales de las Zonas Veredales; la segunda da cuenta de las respuestas institucionales frente a las exigencias sociopolíticas de las comunidades campesinas; la tercera expondrá las disputas regionales en torno a la administración de justicia y seguridad. En la última compartimos algunas reflexiones sobre el significado que la Zona Veredal tiene para La Macarena.

\section{Las Zonas Veredales como expresión de fin del conflicto armado}

Una de las principales condiciones que definieron la negociación entre el estado colombiano y las FARC EP fue que esta se desarrolló en medio de la guerra. No solo la posibilidad de un cese bilateral quedó condicionada a que este fuera definitivo (pues el estado no quería perder el ritmo de su avance militar en contra de las guerrillas) sino que el espíritu de los acuerdos establecía que "nada está acordado hasta que todo esté acordado".

A pesar de los reiterados ceses unilaterales del fuego decretados por las FARC EP y algunas medidas de desescalamiento asumidas por el gobierno Santos (en particular, el cese de bombardeos en marzo de 2015, [El tiempo, 2015]) el modelo de negociación en medio de la guerra desembocó en el desgaste de las conversaciones: tras el ataque de la guerrilla el 16 de abril de 2015 a una patrulla militar acampada en instalaciones civiles (allí murieron once soldados [El tiempo, 2015b]), la respuesta gubernamental consistió en reanudar los bombardeos; el 22 de mayo de 2015 fue atacado un campamento donde comandantes de la guerrilla recién llegados de la Habana daban cuenta de los avances del proceso de paz entre sus combatientes; allí murieron 26 guerrilleros, entre ellos el Comandante Jairo. Ese mismo día las FARC- EP cancelaron el quinto cese unilateral que habían declarado seis meses antes. Jairo fue un mando con larga trayectoria en el Bloque Sur, de amplio reconocimiento político en comunidades del norte del Caquetá y conocido en el país por su papel como responsable del control de San Vicente del Caguán durante la "zona de despeje", 1998-2002 (WN, 2015)

A pesar de la reactivación de la guerra, las paradojas de unas negociaciones en medio del fuego daban cuenta de una situación particular: las acciones humanitarias conjuntas no se detuvieron, como lo fue el desminado de la vereda El Orejón en Briceño, Antioquia. Y aunque según el Alto Comisionado de paz Sergio Jaramillo (El País, 2015), estas acciones daban cuenta del desescalamiento del conflicto, este no fue tal. Tanto así que el fin del cese unilateral de las FARC EP y la reactivación de los bombardeos de las FF.MM llevaron a una sucesión de ataques a la infraestructura y acciones bélicas que llevaron el proceso de paz a uno de sus puntos más críticos. Tras un llamado urgente de los países garantes del proceso de paz para construir un ambiente favorable para las negociaciones, el 12 de julio de 2015 fue anunciado en La Habana que "El Gobierno Nacional, a partir del 20 de julio, 
pondrá en marcha un proceso de desescalamiento de las acciones militares, en correspondencia con la suspensión de acciones ofensivas por parte de las FARC” (OACP, 2015).

Aunque estos esfuerzos no supusieron, pues, una tregua formal, permitieron redefinir la naturaleza de las negociaciones: tanto el estado, las FARC EP y distintos sectores sociales pudieron confirmar con los meses la seriedad de las mismas. En el terreno y durante nuestro trabajo de Campo en la Sierra de La Macarena nos fue posible corroborar en distintos lugares y episodios que desde agosto de 2015 existieron franjas desmilitarizadas y protocolos para coordinar el desplazamiento de destacamentos tanto de las FF.MM, como de las FARC EP. En distintas ocasiones donde se dieron violaciones a los pactos-no-formales, las comunidades campesinas y autoridades locales tuvieron la capacidad y potestad de mediar, como fue el caso de los llanos del Yarí en enero de 2016 cuando las comunidades se acercaron a una brigada móvil que adelantaba operativos en contra de un grupo de altos comandantes de la guerrilla. Representantes sociales les exigieron que no solo no afectaran a la población civil, sino que además no pusieran en riesgo el proceso de paz (Espinosa 2016).

Ahora bien, puesto que el desescalamiento permitió construir y confirmar la confianza entre las partes sobre la seriedad de la negociación, los casi dos años de tregua no-formal permitieron augurar la inevitabilidad del fin de las hostilidades. Esta fue pactada en el capítulo especial del acuerdo para el cese bilateral y definitivo firmado el 23 de junio de 2016 (El Heraldo, 2016). Tanto en medios de comunicación como en redes sociales fue titular y tendencia el llamado de las FARC para que este fuera "el último día de la guerra" (FARC EP, 2016), un mensaje compartido de forma inicial por el comandante "Carlos Antonio Lozada" (El Tiempo, 2016).

Semanas antes del día del fin de la guerra, nos enteramos que como lugar para verificar el cese bilateral y definitivo serían establecidas unas "zonas de ubicación” o "zonas de concentración”. En La Macarena y en aquellas zonas donde la guerrilla ha ejercido presencia histórica fueron comunes las especulaciones del lugar dónde estarían ubicadas. En septiembre de 2016 existía una idea más o menos clara a este respecto en el país (LSV, 2016) y una menos clara sobre su naturaleza: un lugar temporal, sin mayor infraestructura, que según el Presidente Santos se ubicarían "en unas comunidades que están alejadas de la población" (Presidencia 2016:sp; énfasis por fuera del texto). Aunque tal vez se haya tratado de un lapsus semántico-territorial, cuando el gobierno nacional da cuenta que se trata de comunidades que no hacen parte de "la población", reproduce un esquema mental de marginalización de vastos territorios de la nación que ha sabido permear las instituciones colombianas y sus políticas; esquemas que tal vez ponen en riesgo la implementación de los acuerdos, pues poco se han superado a pesar de la aguda crítica de la desconexión política entre los centros de poder y las periferias sociales marginalizadas realizada por varias analistas, entre ellas Serje (2005), Bolivar (2006), Torres (2011); Gómez \& Ramírez (2015), Carvajal (2017) y otros tantos, entre ellos Vázquez (2014) y el trabajo de ODECOFI dirigido por el padre Fernán González (2008).

El Observatorio Colombiano para el Desarrollo Integral, la Convivencia Ciudadana y el Fortalecimiento institucional en regiones fuertemente afectadas por el conflicto armado, ODECOFI, fue un Centro de Excelencia financiado por COLCIENCIAS que integró distintos grupos de investigación y Universidades del país. Bajo la dirección del padre Fernán fueron publicaron una serie de trabajos que permiten tener un "....acercamiento a la dimensión territorial del conflicto y su relación con los procesos de configuración social de las regiones y subregiones” (Gonzalez, 2012:7). Entre estos trabajos se encuentran, además, los de Vázquez et. al. (2012) y Aramburo et.al (2011) 
Volviendo al tema y a nuestra comunidad, según los testimonios que obtuvimos en La Macarena tanto de parte de líderes sociales y políticos como de funcionarios del estado central, pudimos predecir que las Zonas Veredales serían espacios mucho más amplios -en sentido político- que los presupuestados. Las Zonas no solo permitirían el desarme y reintegración de la fuerza guerrillera sino que servirían, por un lado como anclaje territorial para la reconstrucción de las FARC EP como Partido Legal y por otro como centros pilotos de implementación de los acuerdos ${ }^{\mathrm{iii}}$. Y si bien el partido derivado de las FARC EP tal vez resulte en un partido marginal, como prevén analistas electorales (cfr. El Espectador, 2016), de todas maneras este será representación al fin y al cabo de esas comunidades que marginadas por la lectura oficial (alejadas de la población, dice el gobierno nacional) que para la historia del país representan esa expresión de una nación insurgente que habiéndose levantado en armas encuentra en los acuerdos de la Habana las posibilidades para su integración. Es por ello que las Zonas Veredales resultan claves para comprender los alcances de la transición, la naturaleza de la normalización y las posibilidades de la construcción de paz.

A pesar de los anuncios y a pesar del apoyo de todos los sectores sociales del Municipio al proceso de paz, en La Macarena nos fue común encontrar un generalizado escepticismo frente a la materialización del Acuerdo, bien fuera por las desconfianzas históricas que allí existe hacia la guerrilla, hacia el estado o hacia ambos. Estas actitudes que no se transforman a punta de titulares hicieron que la noticia del "último día de la guerra" fuera incluida en el inventario regional de los cada vez más desgastados anuncios históricos. Sin embargo, la noticia del establecimiento de las Zonas Veredales tenía dos salvedades: primero, el anuncio de la rápida dejación de armas pactada a seis meses y segundo el carácter delimitado de las Zonas. Esta última condición permitió tranquilizar varios sectores del país e incluso comunidades de La Macarena para quienes resultaba problemática la relación entre Zona Veredal y "Zona de Despeje", pues dada la experiencia del fracasado modelo de negociación sustentado en la desmilitarización de varios municipios de la región para las negociaciones entre el gobierno Pastrana y las FARC EP, 1998-2002, un nuevo "despeje" resulta irracional. La delimitación y verificación de las Zonas calmó estas expectativas en tanto auguraba un desarme definitivo, en un plazo establecido en un lugar verificable.

Esta posibilidad contradijo de manera tajante la retórica local de la guerrilla y sus bases sociales en La Macarena, para quienes el desarme -según decían- sería gradual y conforme la implementación de acuerdos. En los discursos locales insurgentes estaba presente que años atrás el comandante Jorge Briceño ("El Mono Jojoy”, q.e.p.d.) decía que "El fusil es el garante de los acuerdos que se firmen. Si uno los entrega, esto se acaba" (Semana, 2010). Y aunque esta es una de las razones que esgrime la disidencia guerrillera que quedó en la región, la dejación de las armas es una posibilidad que existe en los referentes retóricos de sus mártires: el mismo comandante Briceño tenía claro que "Las FARC son muy serias en sus planteamientos sobre el proceso de conversaciones para buscar una salida civilizada distinta a los tiros (...) Estamos dispuestos a hacer lo que sea para buscar salidas dialogadas" (Semana, 2010). En efecto los acuerdos ratificaron que las FARC EP estaban dispuestas al desarme y a su transición como partido político legal en donde, según su máximo comandante, su "única arma será la palabra" (FARC EP, 2017).

En suma, como apuesta central por la paz la confirmación de la transición de la lucha armada a la lucha legal significó, pues, la confirmación definitiva de la voluntad de paz entre las partes, como quedó planteado en el punto de los Acuerdos que establecieron las Zonas Veredales. Ahora bien, 
aunque estos establecieron que estas Zonas serían la espacialización de una metodología de procedimiento, de limitada extensión y 180 días de duración- a fuerza de los hechos las Zonas dieron lugar a una apuesta territorial por la paz que, aunque trascendió los objetivos originales, no traicionó sus propósitos fundamentales.

Tales objetivos fueron redimensionados por tres situaciones definitivas: primero, tras perder el plebiscito el 2 de octubre (cfr. LSV 2006b) el inicio del “día D-1" se vio aplazado, es decir, la concentración formal de la guerrilla quedó pendiente. Los sitios donde los frentes guerrilleros se encontraban fueron denominados puntos de pre-concentración y las zonas a donde se dirigirían entraron en una especie de limbo jurídico, pues sin la confirmación popular de los acuerdos no se iniciaría la construcción de las mismas ni el mandato de la ONU sobre ellas podría tomar efecto.

En segundo lugar, el gobierno nacional se mostró reacio a la adecuación material y construcción de infraestructura para alojar las tropas guerrilleras, pues aspiraban a que las FARC EP levantaran campamentos móviles como lo hicieron durante décadas (Semana, 2017). Pero las FARC EP tenían claro que esos campamentos no eran móviles y no eran campamentos: eran los escenarios para su tránsito a la vida civil; es decir, necesitaban infraestructura, no cambuches (Eje21, 2017). Puesto que las Zonas Veredales darían paso a 'Espacios Territoriales de Capacitación y Reincorporación' (Caracol, 2017) el gobierno nacional nombró una gerencia para su construcción y adecuación; los trabajos se tomaron más de los 180 días estimados para la duración de las Zonas. En tercer lugar, el calendario de la dejación de armas se aplazó 20 días dada (El heraldo, 2017) la dificultad para instalar los contenedores donde la ONU guardaría todo el material de guerra y de acuerdo a versiones que dieron a entender que la guerrilla esperaba contar con la libertad de su gente detenida (El País, 2017).

Finalmente, el 27 de junio de 2017 (El Espectador, 2017b) la dejación de armas se cumplió en su totalidad y las Zonas Veredales continuaron sirviendo como lugares de capacitación, reincorporación y como escenario dinamizador de una nueva realidad social para la cual la transición parece no haber sido prevista ${ }^{\mathrm{xv}}$.

\section{La Zona Veredal y el experimento institucional: un estado normal en tiempos de transición.}

El 11 de mayo de 2017 la comunidad de Playa Rica se declaró en paro cívico indefinido (RCN 2017). Con troncos y piedras bloquearon las rutas de acceso a la ZVTN Urías Rondón y la vía que comunica a San Vicente del Caguán con La Macarena (RCN 2017b). Las reivindicaciones recogían los incumplimientos de las promesas del gobierno, en particular y con nombre propio las de la Oficina del Alto Comisionado de paz, Sergio Jaramillo. Las quejas tomaban en cuenta la falta de prestación de servicios de salud y otra serie de temas en donde, según el testimonio de Gustavo Pérez, uno de los líderes locales

el objetivo del paro es visibilizar la problemática que se ha causado a raíz de la contaminación [del acueducto veredal] por la construcción de la zona campamentaria, que haya mejoramiento de las vías y otro tema es que haya conectividad [eléctrica] para toda la región. Referente a eso pues tenemos unas medidas, que es obstruir el paso que comunica los dos municipios (NC, 2017).

Ese mismo día la comunidad dirigió una carta al Alto Comisionado de Paz, al Alcalde y a la Gobernadora del Meta, la comunidad de Playa Rica en donde reiteran que: 
Como comunidad campesina y trabajadora que ha acompañado el diálogo como la ruta para la construcción de un país en paz, reiteramos nuestra disposición para mantener el paro indefinido en la ZVTN hasta que se atiendan nuestras... pretensiones. (CORPOADYARI, 2017, p.2)

Once días después, la comunidad de la Cristalina (cercana a Playa Rica) se unió a la protesta bloqueando la vía alterna que hacia La Macarena que por allí pasa. La Asociación Campesina de este lugar ASOPEROC, manifestó que hasta no ver cumplidas las "siguientes necesidades" (sic) no levantarían el paro: ampliación de vías, interconexión eléctrica, comunicación telefónica de la región, puente sobre el río lozada y médico para el centro de salud (ASOPEPROC, 2017).

El bloqueo de esta vía y en especial el bloqueo de ingreso a la Zona Veredal significó una nueva forma de protesta para las comunidades de la región, acostumbradas desde hace mucho tiempo a movilizarse hacia afuera (hacia el casco urbano del Mpio. por ejemplo) para ser escuchadas. Ahora pueden hacerlo sin tener que salir y con la posibilidad efectiva de recurrir a los más tradicionales de los repertorios disponibles en la viña del señor para exigirlas: las marchas, las pancartas, los bloqueos, la toma de instalaciones y como ha sido moda reciente, las arengas en las redes sociales verbigracia de la conexión a internet que el Ministerio de Comunicaciones ha dispuesto a lo largo y ancho de la región.

Las movilizaciones se han visto impulsadas, es cierto, por el cambio de actitud gubernamental que tiende a descriminalizar la acción colectiva, pero sobre todo porque ya hay hacia quien orientar tal acción en el territorio. La implementación de la Zonas y la presencia de una sede del Mecanismo de Monitoreo y Verificación (MM\&V) ha implicado que haya presencia del estado central para reclamar tanto por las promesas presentes (la coyuntura), las pasadas (la deuda histórica) como por las que se esperan para el futuro (las de los acuerdos de paz). El bloqueo, que tomó las dos últimas semanas de mayo de 2017, no ha sido la única manifestación de su estilo en el país: desde su instalación por lo menos en otras dos Zonas Veredales -Carrizal, en Antioquia (El Espectador, 2017); Filipinas, en Arauca (El Tiempo, 2017)- han sido bloqueadas en situaciones similares. En Playa Rica la historia se zanjó con el levantamiento del paro la primera semana de junio de 2017, previo acuerdo con representantes de la Alcaldía y la Gobernación del Meta quienes se comprometieron, como no podía ser de otra manera, al cumplimiento de nuevas promesas (RCN, 2017)

Estos episodios ilustran la dificultad que enfrenta la institucionalidad colombiana para garantizar la inclusión de las poblaciones históricamente marginadas, esas que el gobierno entiende como comunidades lejanas de la población, no solo dentro del imaginario de la nación sino dentro de la cobertura del estado de derecho. La capacidad para integrar estas regiones y fortalecer la capacidad institucional que allí ha de funcionar plantea uno de los mayores retos de la construcción de paz para el estado: la reconstrucción de la legitimidad y la soberanía en territorios donde su presencia ha sido, históricamente, de carácter contrainsurgente. Si bien el énfasis y la estrategia puede cambiar, en principio ni las consecuencias de la guerra civil ni la capacidad institucional del estado se superan vía decreto presidencial.

En este orden de ideas son varios los retos que plantean las ZVTN. En primer término debemos tener en cuenta que el proceso de desarme y reintegración de excombatientes difiere de las experiencias previas que hemos tenido en el país, pues este no se desarrolla de manera escalonada, es decir, en destinos pasos según las estructuras militares (Cfr. Herrera y González, 2013). En este sentido, hay un desborde de las capacidades institucionales ya que el proceso tal y como está diseñado exige una 
capacidad logística y financiera que no cuenta, en estos territorios, con instituciones anexas que faciliten su operatividad.

Así pues, una de las primeras dudas que surgen con este problema es el papel de los entes municipales en la descentralización de los procesos y recursos. Al respecto, Hannah Leonardsson y Gustav Rudd expresan que la construcción de paz depende en gran medida de la capacidad de las instituciones nacionales para establecer diálogo con entes locales puesto que a través de ellos es posible lograr la interacción entre el nivel nacional y las comunidades. Es decir, un diálogo de esta naturaleza permite -mediante la inclusión y participación pública- la construcción de legitimidad (Leonardsson y Rudd, 2015). No obstante, la lógica de instituciones del estado no solo se muestra desconectada entre sí, sino que además aleja a las Comunidades de las posibilidades de participación.

Esta desconexión la vimos en mayo de 2017 en Playa Rica, en el marco de una reunión informativa para las comunidades sobre los Planes de Desarrollo con Enfoque Territorial dispuestos en los acuerdos. Representantes de la Zona Veredal y del MM\&V, de las organizaciones sociales de la región y de la Cumbre Agraria (como gestores de la metodología a seguir), junto a delegados de la Oficina del Alto Comisionado de Paz y de la Alta Consejería para el Post Conflicto. El mensaje era claro: las comunidades son las principales gestoras de los planes de Desarrollo y el enfoque territorial supone su efectiva participación. Como paso previo a tales planes, la Alta Consejería para el Post Conflicto inició una prueba piloto en Playa Rica para realizar una caracterización sociodemográfica que no necesariamente recoge las inquietudes de otras instituciones, aunque apoye a varias (como a la Agencia Nacional de Tierras).

Lo que resultó más inquietante para los líderes sociales es que la metodología no fue consultada con ellos, no fue complementada con asuntos que a las comunidades les interesa, y quizá lo mas complicado: la caracterización no fue blindada frente al papel que la información recogida puede jugar en el marco de las acciones jurídicas que en la actualidad el estado adelante en contra de varias miles de familias campesinas a quienes se les acusa de vivir de manera ilegal en predios de la guerrilla (Espinosa 2017). Una reunión de urgencia fue citada y un representante de la Alta Consejería del Post Conflicto señaló que, de no realizarse el piloto, Playa Rica quedaría por fuera de la posibilidad de regularizar sus tierras. Dijo el representante que, puesto que la información recogida es para avanzar en la titulación, la gente puede confiar en la seguridad de los datos recogidos. En un futuro tal vez sea posible pensar en coordinar metodologías e invitar a representantes de las comunidades para que apoyen el diseño, pues según nos dijo, quienes la hicieron tuvieron en mente veredas de la sabana de Bogotá (donde hay energía, conexión a internet, señal de celular, caminos transitables) y no las condiciones de veredas de las sabanas del Yarí. Sin embargo, la prueba piloto fue realizada: las comunidades decidieron confiar, pues estos funcionarios en cuestión (a pesar de la novedad de la agencia que representan) son gente conocida y respetada en la región.

En otro orden de ideas, aunque los delegados de la Oficina de la Alta Consejería de Paz suelen citar en sus alocuciones trabajos de índole académico que dan cuenta de la forma como se han adelantado otras negociaciones y postconflictos (para destacar las fortalezas del modelo colombiano), otros tantos trabajos académicos que dan cuenta sobre la perspectiva de la construcción de paz parecen escapar a su buena voluntad y a la capacidad de las instituciones que se aprestan a la implementación de los acuerdos. Por ejemplo, Ken Menkhaus (2007) expone que en casos de estados débiles o de soberanía fragmentada, la paz debe construirse desde una perspectiva desde abajo que involucre tanto a entes 
gubernamentales como a organizaciones civiles a nivel local. Así pues, la gobernabilidad y soberanía estaría garantizada a través de un estado mediado, es decir, de una instancia estatal que articula tanto las directrices nacionales como las perspectivas y significados a nivel local.

Aunque paradójico, un ejemplo de ello fue un modelo de contratación que empleo el Plan Nacional de Consolidación Territorial a mediados de 2014 en uno de los Municipios del Area de Manejo Especial de la Macarena. En este modelo (previa autorización de los comandantes locales de las FARC EP, por supuesto), las Juntas de Acción Comunal eran las encargadas de ejecutar los proyectos de inversión social, es decir, no había contratista o intermediario en las relaciones pues el diálogo fue directo entre la institucionalidad y las comunidades, y entre emisarios de tal institucionalidad y las FARC EP; cabe anotar que las FARC EP, según nos dijeron representantes de la comunidad en cuestión, reconocieron un importante descuento en el porcentaje que solían cobrar para la realización de obras: del $20 \%$ bajaron al 5\%, pues se trató de una obra hecha por comunidad.

$\mathrm{Al}$ respecto de esta experiencia, José, un funcionario de una de las Agencias del estado reformuladas para la implementación de los acuerdos, reconoce que el modelo de contratación directa con las JAC disminuyó los tiempos de ejecución de los proyectos y a su vez permitió construir una relación de confianza con las comunidades, pues al haber mayor control social sobre la inversión y mayor equilibrio político, las comunidades lograron trabajar conjuntamente con las instituciones y estás reconocer el capital social de las organizaciones de base. No se perdió un solo peso, las obras quedaron bien hechas y allí donde sobró dinero ("¿cuándo sobra dinero en una obra construida por administraciones locales?” se preguntó José) la comunidad lo reinvirtió en nuevas obras. Sin embargo, esta hazaña no prosperó: cuando se hizo noticia y otras comunidades reclamaron de la Alcaldía por la diferencia entre las pésimas, lentas y carísimas obras realizadas por sus contratistas y por las obras que realizan las comunidades, la Alcaldía se quejó ante delegados de Consolidación territorial y el modelo terminó; Consolidación Territorial no quería entrar en polémicas con las administraciones locales de la Sierra de La Macarena.

Hay que tener en cuenta que la posibilidad de involucrar a las localidades en los planes de desarrollo territorial, aunque es loable en su espíritu, puede resultar contraproducente. En contextos donde a pesar del estereotipo de ser zonas guerrilleras los entes locales están cooptados por redes económicas y políticas clientelares asociadas al bipartidismo tradicional, como es el caso de todos los municipios aledaños a la Sierra de La Macarena (incluido San Vicente del Caguán), la definición local de las obras no será más que la reproducción de la ineficacia y corrupción reinantes. Para prevenir esta situación una de las propuestas que ha tomado fuerza en la región (desde distintas voces, una de ellas las nuestras) consiste en buscar una manera concreta y efectiva para involucrar a la sociedad campesina en la definición de los Planes de Desarrollo con Enfoque Territorial a través de las organizaciones comunitarias y sociales, sino también en la planeación y ejecución directa por medio de presupuestos participativos. Esta propuesta fomenta procesos de intervención y fiscalización social que se apoya a su vez en el conocimiento y experiencia de las comunidades para la puesta en marcha de políticas públicas territoriales. En este sentido lo local no deviene a ser únicamente el lugar, sino como señala Torres, sino que este “....se convierte en un objeto de construcción, una herramienta para dar respuesta a los problemas de una comunidad” (2013, p. 327).

De alguna manera, el enfoque territorial de las comunidades campesinas del Yarí demanda esto: la participación efectiva, no solo la invitación a dar información para rellenar caracterizaciones. Esta 
reflexión nos regresa a dos puntos anteriores: las reuniones con el MM\&V y el paro de Playa Rica. Es en un escenario de normalización de este tipo, donde la presencia institucional es mas bien precaria y vertical, que para la gente se hizo necesario que el $M M \& V$ sirviera como puente entre el nivel local y nacional, con los resultados que antes hemos comentado. Tan es así, que en su momento tanto los verificadores de la ONU como los delegados del gobierno nacional y de las FARC han preferido cancelar todo canal de comunicación con las comunidades y desatender sus peticiones. Esta respuesta ha generado indisposición de la comunidad para trabajar conjuntamente y ha sido un obstáculo para reconstruir la percepción social que hay del estado en la región; a pesar de las actividades cívicopolicial-insurgentes (Marcha Patriótica 2017) y los diagnósticos censales realizados por "Alta Consejería para el Posconflicto, Derechos Humanos y Seguridad" (ACPDS 2017), para las comunidades de la región el estado es considerado como un "ente lejano" cuya presencia efectiva reside únicamente en las ciudades.

Es por lo anterior que la presencia institucional en la región demanda rapidez y eficacia. Como lo señalara uno de los participantes en la reunión de mayo en Playa Rica, de la forma como les cumplan a los excombatientes y a las comunidades, depende la fuerza que pueda tomar la disidencia de la guerrilla que no se acogió al proceso. Los vacíos de poder que en la actualidad existen en la zona han sido copados por estas disidencias, quienes contrario a la institucionalidad "garantizan" seguridad, justicia inmediata y expedita.

En este sentido, no puede pensarse construir legitimidad y democracia en regiones donde el estado aún no logra hacer mayor presencia ni demostrar mayor reconocimiento de las trayectorias políticas y sociales de las comunidades. El llamado es, por ende, a iniciar procesos escalonados que permitan resolver las exigencias de las comunidades y a su vez, construir junto a ellas procesos de democratización y legitimidad estatal.

\section{Historias Paralelas: los retos de la normalización en medio de una transición enredada}

A partir de los conflictos expuestos en la sección anterior, a continuación, expondremos con mayor detalle los retos que en materia de seguridad y justicia rodean a la Zona Veredal. Para ello ilustraremos a partir de cinco viñetas etnográficas recolectadas durante nuestro trabajo de campo los temores de las comunidades frente a los vacíos de poder dejados por las FARC y las respuestas institucionales frente al aumento de la delincuencia común en la región.

I: Desde diciembre de 2016, la Unidad Policial para la Edificación de la Paz (UNIPEP) hace presencia en el caserío de Playa Rica. La mayoría de las actividades que realizan los policías adscritos a la UNIPEP son de carácter comunitario: hacen aeróbicos en el polideportivo del caserío, ayudan a arreglar motobombas y acompañan actividades lúdicas y de recreación. Para Rafaelv ${ }^{v}$ miembro de la UNIPEP el mayor reto que afrontan es hacerle ver a la gente que el estado ahora es quien gobierna y que es a través de "las leyes nacionales y los protocolos internacionales" en que deben ser resueltos los conflictos.

II. Para Agustín, líder comunitario de Playa Rica, la presencia de la policía en el caserío no garantiza seguridad alguna:

Ellos vienen aquí como pedro por su casa. Desconocen la tradición social y organizativa de la región y pretenden hacer orden sin contar con nosotros. El otro día se presentó una riña en una discoteca, 
íbamos a amarrar al revoltoso a un palo para que se calmara y la policía nos acusó de violar los Derechos Humanos. Ahora resultamos ser nosotros los criminales.

III. Durante una reunión convocada por el $\mathrm{MM} \& \mathrm{~V}$, varios líderes comunitarios denunciaron el aumento de la delincuencia común en la zona: Don Francisco, denunció una ola de abigeato en la vereda el Yamú, mientras Casimiro contó cómo el tesorero de un a de las JAC cercanas a el Rubí fue atracado en la vía que conduce a San Vicente del Caguán. Ante el panorama, los líderes exigían mayor presencia de la Fuerza Pública y resultados concretos, pues "cuando estaba la guerrilla estas cosas no pasaban". Sin embargo, el MMYV expresó que no era parte de sus funciones garantizar la seguridad en la región, además no era posible "poner un soldado o policía en cada finca". Al final, varios líderes expresaron que "siendo así la cosa, va a tocar a nosotros mismos defendernos".

IV. Pasó en una vereda cercana al río Tunia: siete encapuchados entraron a una finca, amarraron a sus habitantes y hurtaron el dinero que allí había. Al regreso de uno de los trabajadores, las personas fueron desatadas y una reunión de emergencia fue citada en la comunidad. A los pocos días dieron con la identidad y paradero de los malhechores: fueron jóvenes de la región, incluso familiares de familias de la vereda. El castigo fue inmediato: regresar el dinero, pagar una multa y trabajar una semana en el arreglo de una carretera. De lo contrario, serían entregados a las Fiscalía. Los jóvenes, con vergüenza, aceptaron el castigo; tres de ellos decidieron irse de la región tras cumplir con el castigo.

V. En otra vereda del Yarí una niña de cinco años fue violada. La gente de la comunidad se reunió y tras escuchar los pormenores del asunto se dieron a la búsqueda del responsable, quien al verse acorralado confesó. En tiempos de la guerrilla eso le hubiera significado una muerte segura; hoy día el comandante de la región envió razón que ellos ya no podían acoger caso alguno. UN líder regional de La Asociación Campesina dio la orden de entregar el acusado a la fiscalía en La Macarena. Una comisión campesina se desplazó al pueblo con la víctima, otra comisión llevó al acusado y lo entregó a la Policía Nacional. La madre de la víctima interpuso la denuncia del caso.

Estas viñetas etnográficas recolectadas durante tres visitas de campo el primer semestre de 2017 plantean los retos de la construcción de paz en materia de seguridad y justicia. Para las comunidades el mayor riesgo que implica el posconflicto son los vacíos de poder dejados tras el desarme y desmovilización de las FARC EP, así como la incapacidad del estado para garantizar la seguridad de los pobladores. En este sentido, uno de los principales obstáculos que logramos observar en la región es la falta de reconocimiento por parte de las instituciones a las instancias comunitarias de justicia. Esto se desprende del testimonio de Rafael, miembro de la UNIPEP, para quien la justicia comunitaria va en contravía y detrimento de la legitimidad estatal, pues no funciona de acuerdo a los lineamientos de la constitución política y las leyes nacionales.

Sin embargo, a partir de nuestros trabajos académicos en la región, hemos encontrado que tales instancias, como consecuencia de la gramática social impuesta por la violencia, han sido capaces de modelar la forma como sujetos y comunidades asumen sus respuestas sociales a la guerra. Han supuesto, pues, instrumentos de empoderamiento colectivo.

Al respecto el líder campesino Gustavo Pérez expresa con preocupación el desconocimiento del MM\&V y de la UNIPEP sobre las instancias de justicia comunitaria, pues si bien reconoce la importancia de que sea el estado quien imparta justicia en casos que lo amerita (las violaciones, los homicidios) es deber también de la institucionalidad reconocer el acumulado histórico, político y 
organizativo de la región: “si ellos reconocieran nuestras formas de organización sería mucho más fácil garantizar nuestra seguridad”. La perspectiva del pluralismo jurídico plantea, como ha sido la experiencia de muchas zonas de influencia guerrillera, escenarios de construcción regional capaz de reconstruir comunidades por medio del trámite de conflictos sociales.

Esta pretensión local y su enfoque territorial se propone integrar tanto las instancias de justicia comunitaria como las instancias de justicia estatal, ya que en este escenario de normalización sin transición (en donde aún no hay una presencia total de las instituciones del estado y perviven los conflictos socio-políticos regionales) es necesario el trabajo conjunto y la coordinación entre diversas instancias y órdenes. Esto como apuesta para prevenir que los vacíos de poder dejados por las FARC EP pueden ser capitalizados por las disidencias, quienes dicen garantizar -contrario al estado- control eficaz y acción inmediata frente a los problemas de seguridad. En una reciente reunión de la disidencia con campesinos de la región aseguraron que ellos, la disidencia, respetará las determinaciones que cada Junta tome frente a los problemas que resuelvan.

En suma, la legitimidad del estado y la posibilidad de la construcción de una sociedad regional que no de espacio a agentes de violencia privada depende en buena medida de la forma como la institucionalidad asuma el reconocimiento de las condiciones históricas particulares del territorio. La perspectiva de los acuerdos en su enfoque territorial y participativo permite observar con creatividad la experiencia social que existe las áreas de influencia de las Zonas Veredales. Es allí donde la articulación entre la soberanía estatal (aun poco reconocida por las comunidades) y las ya sedimentadas soberanías locales permitirá construir escenarios de transición efectivos (cfr. Caraballo 2013, Arévalo 2014).

\section{Reflexiones sobre la Zona Veredal y su significado regional}

La experiencia de pasados procesos de paz dejaron su huella en la Sierra de La Macarena. En particular las negociaciones de "la Uribe" (1982-1987) y "el despeje" (1998-2002), que al implicar la construcción de unas territorialidades especiales, significaron para la región consecuencias significativas en su devenir social. El despliegue guerrillero tras el bombardeo a los campamentos del proceso de la Uribe (Casa Verde, en particular), la división territorial a partir de las distintas jurisdicciones de los frentes guerrilleros en la región y las distintas actualizaciones de los "nuevos modos de operar" farianos no solo permitieron a las FARC EP avanzar en sus apuestas políticas y militares, sino que ofrecieron al estado coordenadas -más bien imprecisas cuando de afectar a la población civil se trató - para orientar sus esfuerzos contrainsurgentes.

Como nueva territorial para la superación de la guerra, los efectos de largo aliento de la Zonas Veredales como espacios de paz para las configuraciones sociales tal vez puedan dimensionarse a partir de las experiencias de paz y guerra pasadas. Puesto que se trata de un proceso que permitió la transformación de la guerrilla en partido, sin duda, las zonas Veredales representan un significante para el futuro de la región como hito material, como espacio de movilización, como refrendación de la historia insurgente y constatación de las apuestas de paz alcanzadas.

Como estrategia pedagógica, las Zonas Veredales y su propósito de garantizar "el tránsito a la normalidad" de las/os ex-combatientes de las FARC EP han sido el escenario idóneo para mostrar que implica la "normalidad" en cuanto a la relación de las comunidades y de los sectores políticos 
comunitarios con el estado, en sus distintos niveles. Si hasta el año pasado las FARC EP, como organización armada, se entendieron en el más alto nivel con el estado central, la lógica de sus relaciones con representantes locales y regionales del estado varían de manera inexorable. Hasta hace poco tiempo la gestión de obras y el destino de algunos presupuestos pasaba por la autorización de comandantes locales, incluso obras enmarcadas en las apuestas contrainsurgentes del Plan de Consolidación. Ahora, sin la presión de las armas ya no hay forma para que la gestión de tales obras se haga de forma expedita. De esto ha dado cuenta la construcción de las Zonas Veredales y la adecuación de las localidades cercanas a las mismas en donde las FARC EP pudieron dimensionar el tipo de estado con el que negociaron y experimentar de manera directa el tipo de estado con el que las comunidades han tenido que lidiar a lo largo de su historia. La posibilidad de hacer viable el enfoque territorial supondrá, pues, un avance civilizado para balancear legitimidades y expectativas.

Eso sí: el panorama por más crítico que parezca es optimista por naturaleza. Ver soldados, policías y guerrilleros coordinando la seguridad de la Zona, asistir a reuniones con líderes políticos regionales, locales, representantes de las FARC EP y líderes sociales; recibir a funcionarios encargados de políticas públicas que por fin -y casi que por primera vez en la historia- tratan a las comunidades en el marco de la ciudadanía y no bajo los parámetros del Código Penal; ver el regreso de gente que la guerrilla desterró y poder presenciar que las comunidades y asociaciones campesinas tengan la posibilidad de discutir (no tan solo obedecer) con comandantes de las FARC EP el futuro político de la región, dan cuenta de los primeros logros concretos de los Acuerdos de la Habana.

La posibilidad de participación política sin temor a la criminalización, el cese de los combates y los bombardeos, el fin de los ajusticiamientos y de las detenciones, de las amenazas a poblaciones enteras, son algunas de esas situaciones inéditas de carácter positivo que la instauración de las ZVTN ha traído consigo $^{\text {vi }}$.

De otro lado, en La Macarena vemos consecuencias del fin de la guerra que aunque previstas en su momento, han sucedido sin mayor posibilidad de acción por parte de las Comunidades y ante la mirada pasiva de las instituciones del estado: talas de selva virgen, indiscriminadas y masivas, agenciadas por ganaderos provenientes del Caquetá, quienes poco a poco han comprado fincas campesinas y se han hecho a extensas zonas boscosas aledañas a Chibiriquete (pues ya no hay una guerrilla que conserve); hay quienes dan cuenta de la presencia de testaferros de narcotraficantes y paramilitares que han regresado para tomar posesión de hatos que hasta hace poco estuvieron en manos de la guerrilla (ya no hay frentes que regulen la propiedad de otros ilegales); los asaltos a fincas, el robo de ganado y la piratería terrestre se hacen comunes (ya no hay están las FARC EP para cuidar). Estos son los vacíos de poder que retan al estado y a las comunidades.

Sin embargo y dada la magnitud de la apuesta de paz que las zonas veredales encarnan, como hemos dicho antes ellas son una prueba fehaciente de la voluntad entre las partes para cumplir los acuerdos. De igual forma es a partir de la experiencia de la implementación de las Zonas y de los conflictos sociales que alrededor de ella afloraron que quedó claro con qué tipo de estado fue el que se negoció la paz, y que tipo de movilizaciones nos esperan para defenderla.

No obstante, el optimismo reinante en torno a la Zona Veredal Urías Rondón se ve contrastado con una realidad social más bien pragmática: la normalización propuesta como manera de entender la 
superación de la guerra expresada en un funcionamiento "normal" de la sociedad regional encuentra varios problemas, de los cuales destacamos los siguientes:

1. Las Fuerzas Militares no se desprenden totalmente de su carácter contrainsurgente; otro, que, a pesar del carácter marginal de la disidencia de la guerrilla, tiene la capacidad para ejercer su poder.

2. La lentitud institucional para ejercer acciones efectivas y su desconexión con el entramado organizativo local, tal vez como rezago de la perspectiva contrainsurgente del estado, no augura la mejor de las perspectivas para los futuros Planes de Desarrollo con Enfoque Territorial.

3. Así mismo, distintas agendas políticas locales han sabido instrumentalizar la adecuación de la Zona Veredal como un evento para movilizar sus sectores sociales, no solo para pedir lo mismo que allí no se ha visto (i.e. carreteras, centros de salud, adecuación de escuelas, interconexión eléctrica, etc.) sino para reivindicar, a su vez, sus apuestas sociopolíticas y organizativas. El problema con ello es que tales agendas se movilizan en torno a la desacreditación del proceso de paz. Uno de tales posiciones se desprende de las palabras del Alcalde de La Macarena, Ismael Medellín, quien en declaraciones a la prensa malinterpretó la naturaleza de la movilización al decir que "hay una molestia grande con nuestra población (sic) porque las Farc (en la zona veredal) hoy tienen energía, médico y nuestra población carece de varios de estos beneficios". Tanto delegados de la oficina del Alto Comisionado de Paz como de la Alta Consejería del Postconflicto nos comentaron las enormes dificultades que han tenido para hacer entender a la Alcaldía y a delegados de ASOJUNTAS que las posibilidades de inversión regional establecidas en los acuerdos no son exclusivamente las destinadas a la adecuación de la ZVTN y que llegado el momento serán las Comunidades las gestoras de tales inversiones, no necesariamente la alcaldía ni ASOJUNTAS (Testimonios de José y Katerin).

4. La lógica de la movilización política de sectores cercanos a la insurgencia no se desprende de su vocación leninista, en donde la centralización de decisiones pre-establecidas coarta la posibilidad de la deliberación comunitaria. Los procesos democráticos, participativos y abiertos son uno de los retos que espera a la apuesta política insurgente.

5. A diferencia de otras regiones del país, las FARC EP no se han comprometido con acciones públicas de perdón y reparación colectiva ante los graves crímenes cometidos en nombre de la lucha por el pueblo. Esta situación permite que muchas personas en La Macarena desconfíen de las posibilidades de justicia y reparación, mantiene abiertas las brechas que existen entre sectores sociales y cierra puertas a la posibilidad de la acción política legal de la antigua guerrilla.

6. Las garantías de seguridad que ofrece el estado se han visto relativizadas con los avances de la disidencia en zonas muy cercanas a cascos urbanos, con la presencia de grupos armados en la zona sur de El Yarí y con las mínimas garantías que existen para los y las líderes sociales.

7. Algunos procesos de retorno que la paz permite en la actualidad, como los de la comunidad Pijao desplazada por las Farc del Resguardo Yaguara II y como los de numerosas familias que regresan a sus tierras, no cuentan con el acompañamiento ni de la sociedad civil no del estado; la posibilidad de reactivar conflictos pasados está abierta en tanto no existen 
estrategias -ni en las instancias sociales, ni en las estatales- para tramitar instancias que permitan superar la victimización horizontal (Marín, 2017).

8. Todos estos líos juegan en contra de las posibilidades de la construcción de paz y de manera perversa a favor de la disidencia de la guerrilla, en cuanto las demoras e incumplimientos del gobierno, la corrupción, los lentos procesos burocráticos; el excesivo centralismo, las formas de participación poco democráticas la falta de garantías para líderes sociales; las heridas aún abiertas de la guerra y la ausencia de estrategias para tramitar los conflictos comunitarios asociados a esta, dan cuenta de una particular normalización en donde no necesariamente hay transición sino más bien, la reproducción de conflictos en tiempos de paz.

Estos problemas, que no son irresolubles, toman lugar en el delicado y frágil periodo de transición. De la forma como se plantee su resolución y trámite depende una de las apuestas claves para la construcción de la paz estable y duradera que los acuerdos se han propuesto: el entendimiento entre contrarios, la superación de las causas de la confrontación y la justa reinvindicación de las víctimas.

\section{Conclusiones}

La experiencia de las ZVNT da buena cuenta de la naturaleza del proceso de paz y las consecuencias que este implica para la sociedad colombiana, en general y las realidades locales, en particular. En el artículo hemos tratado la forma en que la Zona Veredal Transitoria de Normalización Urías Rondón ha supuesto una experiencia territorial capaz de trascender su propósito inicial de un "lugar" a secas. Es decir, la lógica de su implementación trascendió las expectativas gubernamentales de un espacio temporal para el desarme de combatientes. A fuerza de los hechos la Zona Veredal se ha constituido en un territorio mucho más complejo: allí se cruzan no sólo las contradicciones de la materialización de los acuerdos, sino que han tomado lugar de manera simultánea conflictos sociales pasados y presentes. Esto ha hecho que las apuestas transicionales de los acuerdos encaminadas a la normalización se hayan visto desafiadas por situaciones no previstas, entre ellas la incapacidad del estado para cumplir de manera eficiente su parte de los acuerdos y la posibilidad que encuentran las comunidades para reactivar las movilizaciones colectivas en un escenario de paz.

En el caso particular de la región que antes hemos mencionado, entre los retos que supone la construcción de paz se encuentran la superación de la naturaleza contrainsurgente de la presencia estatal y del carácter vanguardista en la apuesta política de las FARC EP; la apertura de espacios y canales de participación democrática en las comunidades, la superación de la instrumentalización de la violencia de parte de sectores regionales (ya nadie podrá echarle la guerrilla a nadie, o cobrar deudas pendientes con una denuncia a las FF.MM) el reconocimiento gubernamental del enfoque de autonomía territorial de las asociaciones campesinas y la prevención de nuevas violencias.

Sin embargo, uno los efectos tangibles de la firma del acuerdo y el cese de hostilidades tiene que ver con que la gente de la región sienta más cierta y cercan a la presencia del estado en el marco de la Zona Verdal y en figura de la MM\&V como posibilidad para orientar sus demandas al estado de manera inmediata. Que por primera vez las comunidades tengan la posibilidad de transmitir sus inquietudes a instancias que por lo menos les escuchan sin criminalizarles, que hayan podido ver una armoniosa convivencia entre la guerrilla en proceso de desarme y las Fuerzas Militares como garantes de la seguridad de la Zona y que la "presencia de estado" (la principal bandera de movilización 
campesina) se sienta cercana, son eventos inéditos que han transformado la lógica de la región. Estos se expresan en la presencia no militarizada de distintas entidades del estado, un nuevo tipo de relación de las comunidades con la insurgencia, de las comunidades campesinas e indígenas entre sí y de todos estos sectores con la realidad social y orden de cosas que poco a poco se han gestado.

En suma, la situación de posguerra no solo ha traído nuevos conflictos, perpetuado otros (verbigracia la disidencia) sino que también permite tratar de forma civilizada el cúmulo de conflictos anteriores. Cómo no, la instalación de la Zona Veredal estuvo acompañada de anuncios no solo para la adecuación de la Zona (mejoramiento de $40 \mathrm{~km}$ de carreteras, por ejemplo) y la mitigación de sus impactos (uso compartido de las aguas, en particular) sino también para para el mejoramiento de la calidad de vida delos habitantes de Playa Rica, en especial mediante la construcción de un Centro de Salud. Las "promesas de la paz", dice la gente.

Esta sencilla historia que acabamos de exponer y que como evento ha tomado un espacio de tiempo muy corto, en un área geográfica más bien pequeña, condensa un contexto histórico muy amplio: la negociación que pone fin a la guerra. La lógica social en torno a la Zona Veredal Involucra además de distintas narrativas y prácticas sobre la paz, las partes intervinientes en los acuerdos y los destinos agentes de quienes depende la posibilidad de la implementación efectiva de los acuerdos de paz, en particular instituciones del estado y las comunidades. El mensaje para funcionarios y sectores sociales para fortalecer la perspectiva territorial es claro: según el presidente de Asojuntas de La Macarena, Delio Franco, en la región sabemos que, si bien los acuerdos se firmaron en la Habana, la paz la construimos nosotros.

\section{Referencias Bibliográficas}

ACDPS (2017). "En El Meta, inicia estructuración de proyectos priorizados por comunidades y alcaldes". Recuperado de: http://www.posconflicto.gov.co/salaprensa/noticias/2017/Paginas/20170428-En-El-Meta-inicia-estructuracion-de-proyectospriorizados-por-comunidades-y-alcaldes.aspx Consultado el 26 de mayo de 2017.

Arévalo, J. (2014). Construcción de paz y un nuevo modelo de construcción de Estado: una lectura de los dos primeros acuerdos de la Habana. Revista de Economía Institucional, 16 (30), pp. 131-169.

ASOPEPROC. (2017). “Comunicado”. Mimeo.

Bolivar, I. (Ed) (2006). "Identidades Culturales Y Formación Del Estado En Colombia. Colonización, Naturaleza Y Cultura" Editorial Corcas: Bogotá.

Caraballo, V. (2013). "Ordenes locales, acuerdos de paz y presencia diferenciada del Estado. Negociacion con las Milicias Populares de Medellin”. Colombia Internacional, 77, pp. 241 270

Caracol Radio. (2017). “Zonas Veredales se convertirán en 'Espacios Territoriales de Capacitación y Reincorporación”' Recuperado de: http://caracol.com.co/radio/2017/05/30/politica/1496110731_103436.html Fecha de consulta: 30 de mayo de 2017. 
Carrillo, L. (2017). "Cotidianidades desarmadas: el reto invisible de las transiciones territoriales. La ventana abierta de la Zonas Veredales Transitorias de Normalización en el proceso de paz con las FARC EP". Revista El Agora Vol. 17 no 2.

Carvajal, C. (2017). "Potencialidades para la paz de las organizaciones sociales de base en La Macarena, Meta”. Editorial Cinep: Bogotá. Disponible en: http://viva.org.co/cajavirtual/svc0532/pdfs/Anexo_1.pdf\#page=58 Fecha de consulta: 29 de mayo de 2017.

CORPOADYARI (2017). "Derecho de petición por la garantía del derecho fundamental al agua y otros asuntos". Mimeo.

Eje21 (2017). Tensión entre Gobierno y Farc por adecuación de Zonas Veredales. Disponible en: http://www.eje21.com.co/2017/03/tension-entre-gobierno-y-FARC-por-adecuacion-dezonas-veredales/ Fecha de Consulta: mayo 2 de 2017

Espinosa, N. (2016). "Local anxieties in the prelude of the end of the civil war in Colombia". Mimeo.

Espinosa M, N., Ramírez, E. A., \& Gonzalez, E. (2014). La apropiacion politica del territorio. Estrategias de participacion política y de resistencia campesina en los Llanos del Yarí. El Agora USB, 14(1), 177-202. doi:http://dx.doi.org/10.21500/16578031.125

Espinosa M, N., Gonzalez, E., \& Ramírez, E. A. (2012). Etnografía, territorio y conflicto armado. Metodología de una investigación sobre la construcción regional de los Llanos del Yarí (Caquetá, Colombia). El Ágora USB, 12(2), 229-248. doi:http://dx.doi.org/10.21500/16578031.79

El Espectador. (2017) "Mineros y campesinos bloquean ingreso a la Zona Veredal Transitoria de Carrizal”. Recuperado de: http://www.elespectador.com/noticias/nacional/mineros-ycampesinos-bloquean-ingreso-la-zona-veredal-transitoria-de-carrizal-articulo-683859 Consultado el 1 de junio de 2017

El Espectador (2017b). "Hoy termina la dejación de armas de las Farc". Recuperado de: http:/ / colombia2020.elespectador.com/pais/hoy-termina-la-dejacion-de-armas-de-las-farc Consultado: junio 27 de 2017

El Espectador (2016). "La izquierda y la llegada de las Farc”. Recuperado de: http://www.elespectador.com/noticias/politica/izquierda-y-llegada-de-farc-articulo-656720 Consultado el 19 de mayo de 2017.

El Heraldo. (2016). "El último día de la guerra” Periódico El Heraldo. Recuperado de: https://www.elheraldo.co/nacional/el-ultimo-dia-de-la-guerra-268011 Consultado el 20 de mayo de 2017

El Heraldo. (2016b). “Aesinan a líder campesino en San Vicente del Caguán”. Recuperado de: https://www.elheraldo.co/colombia/asesinan-lider-campesino-en-san-vicente-del-caguan303697 Fecha de consulta: julio 12 de 2017

El Heraldo. (2017). "Vemos con buenos ojos el aplazamiento de la dejación de armas": frente 58 de las Farc” Recuperado de: https:/ /www.elheraldo.co/cordoba/vemos-con-buenos-ojos-elaplazamiento-de-la-dejacion-de-armas-frente-58-de-las-farc-367349 Fecha de consulta: julio 12 de 2017 
El País. (2015). “Gobierno insiste en que sí hay desescalamiento de la guerra en el país”. Recuperado de: http://www.elpais.com.co/proceso-de-paz/gobierno-insiste-en-que-si-haydesescalamiento-de-la-guerra-en-el-pais.html Consultado el 16 de mayo de 2017

El País. (2017). "El 31 de mayo no puede terminar la dejación de armas": 'Jesús Santrich'. Recuperado de: http://www.elpais.com.co/proceso-de-paz/el-31-de-mayo-no-puedeterminar-la-dejacion-de-armas-jesus-santrich.html Fecha de consulta: 3 de junio de 2017

El Tiempo. (2017). "Bloquean vía de acceso a zona veredal de las Farc en Arauca" Recuperado de: http:/ /www.eltiempo.com/colombia/otras-ciudades/bloquean-via-de-acceso-a-zonaveredal-de-las-farc-en-arauca-65132 Consultado el 1 de junio de 2017

El Tiempo. (2016). "Qué significa para las FARC la afirmación 'el último día de la guerra”. Recuperado de: http://www.eltiempo.com/archivo/documento/CMS-16627606 Consultado el 14 de mayo de 2017

El Tiempo. (2015). "Gobierno suspende bombardeos contra las Farc por un mes”. Recuperado de: http://www.eltiempo.com/archivo/documento/CMS-15373718 Consultado el 16 de mayo de 2017

El Tiempo. (2015b). "Once militares muertos en el Cauca tras ataque de las Farc". Recuperado de: http://www.eltiempo.com/archivo/documento/CMS-15572175 Consultado el 12 de mayo de 2017.

FARC EP. (2016). “Qué este sea el último día de la guerra”. Página Oficial de las FARC EP. Recuperado de: http://www.FARC-ep.co/comunicado/que-este-sea-el-ultimo-dia-de-laguerra.html Consultado el 20 de mayo de 2017

FARC EP. (2017). "Nuestra única arma será la palabra”. Recuperado de: http://pazFARCep.org/comunicadosestadomayorFARC/item/3560-nuestra-unica-arma-sera-la-palabra.html

Aramburo, C. Barajas, D. Espinosa, M. García, C. Valderrama, D. (2011) “Geografías de la guerra, el poder y la resistencia. Oriente y Urabá antioqueños, 1990-2008”. Iner-Odecofi y Colciencias: Bogotá:

Gonzalez, F. Gutiérrez, O. Matiz, C. Aponte, A. Rodríguez, J. (2012). "Conflicto y territorio en el Oriente Colombiano". Iner-Odecofi y Colciencias: Bogotá:

González, F. (ed.) (2008). "Hacia la reconstrucción del país: desarrollo, política y territorio en regiones afectadas por el conflicto armado". Odecofi-Colciencias-Cinep: Bogotá:

Herrera, D. González, P. (2013). Estado del arte del DDR en Colombia frente a los estándares internacionales en DDR (IDDRS). Colombia Internacional, (77), 272-302. Recuperado de: http://www.scielo.org.co/scielo.php?script=sci_arttext\&pid=S012156122013000100010\&lng=en\&tlng=es. Fecha de consulta: julio 05, 2017

Hoyos, F. (2017). "Territorios entretejidos: La zona veredal de normalización "Ariel Aldana”, Tumaco. (2017). Entre la trama de violencia regional y el horizonte de transición”. Ponencia presentada en el simposio “"Etnografías de la 'normalización’: Dispositivos territoriales transicionales y zonas veredales”, del XVI Congreso de Antropología en Colombia en junio de 2017. Documento inédito.

Leonardsson, H y Rudd, G. (2015). The local turn in peacebuilding literature review of effective emancipatory local peacebuilding. Third World Quaterly. 36 (5), pp. 825-839 
LSV (La Silla Vacía). (2016). “Así son las zonas de concentración de las Farc”. Recuperado de: http:/ / lasillavacia.com/hagame-el-cruce/asi-son-las-zonas-de-concentracion-de-las-farc57804 Consultado el 13 de mayo de 2017.

LSV (La Silla Vacía). (2016b). "Un vistazo a los resultados del plebiscito”. Recuperado de: http://lasillavacia.com/blogs/un-vistazo-los-resultados-del-plebiscito-58200. Consultado el 25 de mayo de 2017.

Marcha Patriótica (2017). "Así conviven y trabajan juntos comunidad, policías y guerrilleros" Recuperado de: http://marchapatriotica.org/index.php/noticias-marcha-patriotica-2/171paz-marcha-patriotica/3862-asi-conviven-y-trabajan-juntos-comunidad-policias-yguerrilleros Consultado el 23 de mayo de 2017.

Marín, K. (2017). "Construcción de paz en escenarios intracomunitaria. Estudio de caso Sierra de La Macarena (Meta, Colombia”. Revista de Estudios Políticos, No. 51. Disponible en: http://aprendeenlinea.udea.edu.co/revistas/index.php/estudiospoliticos/article/view/3251 44

Menkhaus, K. (2007). Governance without government in Somalia: spoilers, Statebuilding and the politics of doing. International Security, 7 (2), pp. 74-105

NC (Nueva Colombia Noticias) (2017). Comunidad de Playa Rica protesta por Incumplimientos. NC Noticias. Recuperado de: https://www.youtube.com/watch?v=T9sVJE8xxPM Consultado 5 de Junio de 2017

OACP. (2015). "Comunicado Conjunto \#55 La Habana, Cuba, 12 de julio de 2015. Recuperado de: http://www.altocomisionadoparalapaz.gov.co/mesadeconversaciones/PDF/comunicadoconjunto-55-12-de-julio-de-2015-v1-3-1436723530.pdf Consultado el 12 de abril de 2017.

OACP. (2016). Texto del Acuerdo Final. Disponible en: http://www.altocomisionadoparalapaz.gov.co/procesos-yconversaciones/Documentos\%20compartidos/24-11-2016NuevoAcuerdoFinal.pdf Fecha de Consulta: mayo 13 de 2017

OACP. (2016b). ABC de las zonas veredales. Disponible en: http://www.altocomisionadoparalapaz.gov.co/procesos-yconversaciones/Documentos\%20compartidos/ABC-Zonas-veredales.pdf Fecha de Consulta: mayo 13 de 2017

Presidencia de la República de Colombia. (2016). Zonas Veredales Transitorias. Disponible en: http:/ / es.presidencia.gov.co/noticia/160818-Zonas-Veredales-Transitorias-no-afectaran-enningun-sentido-la-vida-de-los-colombianos-Presidente-Santos Fecha de Consulta: mayo 13 de 2017

Ramírez, E. Gomez, T. (2015). "La ficción del Estado - Nación. Configuración territorial del Estado en el departamento del Caquetá". Editorial Universidad de Antioquia: Medellín.

RCN. (2017). "Comunidad bloquea entrada de zona veredal en la Macarena, Meta" Recuperado de: http://www.rcnradio.com/nacional/comunidad-bloquea-entrada-zona-veredal-la-macarenameta/ Consultado el 1 de junio de 2017 
RCN. (2017b). “Habitantes de La Macarena Meta protestan cerca de zona veredal” Recuperado de: http:/ /www.rcnradio.com/locales/habitantes-la-macarena-meta-protestan-cerca-zonaveredal/ Consultado el 1 de junio de 2017

RCN. (2017c). "Se acabó la protesta en La Macarena Meta y se levantó el bloqueo a Caquetá” Recuperado de: http://www.rcnradio.com/locales/se-acabo-la-protesta-la-macarena-metase-levanto-bloqueo-caqueta/ Consultado el 1 de junio de 2017

Semana. (2010) “Así pensaba el Mono Jojoy” Revista Semana. Recuperado de: http://www.semana.com/nacion/articulo/asi-pensaba-mono-jojoy/122354-3 Consultado el 16 de mayo de 2017.

Semana. (2017). “Zonas veredales: ¿las Farc llegaron para quedarse?” Revista Semana. Recuperado de: http://www.semana.com/nacion/articulo/zonas-veredales-7000-guerrilleros-no-sabena-donde-ir-luego-de-dejar-las-armas/518925 Consultado el 22 de mayo de 2017.

Serje, M. (2005). “El revés de la nación. Territorios salvajes, fronteras y tierras de nadie”. Bogotá: Ediciones Universidad de los Andes.

Torres. M. (2011). "Estado y Coca en la frontera colombiana. El caso se Putumayo" Editorial Cinep: Bogotá

Torres, J. (2013). Las regiones frente a la justicia transicional. Estudios de Derecho, (LXX) 155, pp. 311-388.

Vázquez, T. (2014). “Territorios, conflicto armado y política. El papel del conflicto armado en la construcción y diferenciación territorial de la región de El Caguán. Amazonía occidental colombiana. Revista El Agora Vol 8. No. 2.

Vásquez, T. Vargas, A. y Restrepo J. (2011). Una vieja guerra en un nuevo contexto. Conflicto y territorio en el sur de Colombia. Odecofi-Cinep, Editorial Javeriana: Bogotá.

WN. (2015). "Entrevista con el Comandante Jairo". Recuperado de: https://wn.com/Entrevista_Con_El_Comandante_Jairo_Martinez_De_Las_FARC_Ep Consultado el 20 de mayo de 2017

\section{Notas:}

iUna versión anterior de este texto fue presentada como ponencia en el simposio "Etnografías de la 'normalización': Dispositivos territoriales transicionales y zonas veredales", del XVI Congreso de Antropología en Colombia, junio de 2017. El trabajo se realizó en el marco de la investigación "Conflictos por la tierra en el post-conflicto", financiada por la Universidad de San Buenaventura y la Academia de Historia del Caquetá.

iiLos nombres que en el texto acompañamos de un apellido son nombres reales. Los demás han sido cambiados a solicitud de nuestras fuentes. Algunos nombres de localidades han sido cambiados. Los testimonios aquí utilizados o bien son de consulta pública, han sido tomados de reuniones abiertas o han contado con el consentimiento informado de el/la entrevistada.

iiiEsto nos lo aseguró José, delegado de la Alta Consejería para el Post Conflicto. Enero de 2017.

Valga la pena anotar que (al momento de publicar este artículo) con el tiempo ya vencido y la dejación de armas concretada, ninguna Zona estaba terminada en su totalidad.

${ }^{v}$ Los agentes entrevistados lo hicieron bajo la condición de anonimato. Los nombres y rangos han sido cambiados

viSin obviar, claro está, que la disidencia es responsable de varias muertes en la región, de amenazas a comunidades que acepten planes de erradicación voluntaria de coca y del cobro de nuevos "impuestos". Como hemos dicho antes, del cumplimiento de los acuerdos será la posibilidad de hacer de esta disidencia un actor marginal en la región. 